\title{
POST-CMOS MODULAR INTEGRATION OF POLY-SIGE MICROSTRUCTURES USING POLY-GE SACRIFICIAL LAYERS
}

\author{
A. E. Franke, ${ }^{\# 0}$ Y. Jiao, ${ }^{\# 0}$ M. T. Wu, ${ }^{* 0}$ T.-J. King, ${ }^{\#}$ R. T. Howe ${ }^{\# * 0}$ \\ "Department of Electrical Engineering and Computer Sciences \\ *Department of Mechanical Engineering, ${ }^{\circ}$ Berkeley Sensor \& Actuator Center \\ University of California at Berkeley, Berkeley, CA 94720-1770
}

\begin{abstract}
Polycrystalline silicon-germanium (poly-SiGe) microstructures have been fabricated on standard CMOS wafers with aluminum metallization. Hydrogen peroxide $\left(\mathrm{H}_{2} \mathrm{O}_{2}\right)$ etches the sacrificial polycrystalline germanium (poly-Ge) layer without significantly etching the p-type poly-SiGe structural layer. In contrast to HF sacrificial release etches, no special protection of the underlying CMOS layers is needed. For the first time, the fabrication of LPCVD surface microstructures directly on top of standard electronics is demonstrated, which leads to dramatic reductions in both MEMS-CMOS interconnect parasitics and device area.

Initial measurements indicate that poly-SiGe has promising material properties. Its fracture strength is $1.2 \pm$ $0.1 \%$, which is comparable to that of poly-Si. A folded flexure lateral resonator has a quality factor in vacuum as high as $\sim 15,000$. No stress or dopant-activation anneal of the structural layer is needed, since the in-situ boron-doped poly-SiGe is found to have an as-deposited stress of only $-10 \mathrm{MPa}$ (compressive) and a resistivity of only $1.8 \mathrm{~m} \Omega-\mathrm{cm}$. From a cantilever-beam array, the strain gradient is found to be rather high $\left(+1.4 \times 10^{-4}(\mu \mathrm{m})^{-1}\right)$, so that a $120 \mu \mathrm{m}$ cantilever bends away from the substrate by $1 \mu \mathrm{m}$ at its tip. Deposition and anncaling conditions have yet to be optimized to minimize strain gradient.
\end{abstract}

\section{INTRODUCTION}

The modular integration of microelectromechanical devices with driving, controlling, and signal-processing electronics is advantageous for improving performance, lowering manufacturing cost, and allowing for separate development of the micromechanics and microelectronics technology components. The microelectronics-first approach has the advantage that it is more conducive to the use of integrated-circuit (IC) foundries for low-cost electronics fabrication. However, it necessitates a low thermal budget for the microelectromechanical structures (MEMS) fabrication process, if conventional circuits employing aluminum or copper interconnects are to be used. A standard polycrystallinesilicon (poly-Si) based MEMS process typically employs deposition temperatures near $600^{\circ} \mathrm{C}$ and annealing temperatures at or above $900^{\circ} \mathrm{C}$ in order to achieve low-resistivity, lowtensile-stress structural films [1]. These temperatures are too high to be compatible with conventional IC metallization schemes. Poly-Ge has been demonstrated as a CMOScompatible structural material, in a process which uses a conventional $\mathrm{SiO}_{2}$ sacrificial layer $[2,3]$. However, integration with CMOS requires a low-temperature, pinhole-free, $\mathrm{HF}$ - resistant film to protect the electronics during the lengthy $\mathrm{HF}$ release etch.

Low-pressure chemical vapor deposited (LPCVD) poly$\mathrm{SiGe}$ has properties similar to poly-Si, but can be deposited and annealed to activate dopants at much lower temperatures than poly-Si $[4,5]$. The high dopant activation found in p-type polySiGe [5] eliminates the need for post-deposition annealing in order to lower the resistivity. $\mathrm{Si}_{0.7} \mathrm{Ge}_{0.3}$ has been used recently as the structural material for surface-micromachined bolometers [6].

This paper describes a micromachining process based on p-type poly-SiGe structural films and poly-Ge sacrificial films, which enables the modular integration of conventional surface microstructures with standard CMOS circuitry. In the initial experiments, no anneal of the p-type poly ${ }_{\mathrm{m}} \mathrm{SiGe}$ structural films was needed to reduce either resistivity or stress. Special protection of the CMOS is unnecessary, since the $\mathrm{H}_{2} \mathrm{O}_{2}$ release etchant does not damage the either the deposited $\mathrm{SiO}_{2}$ passivation layers [7] or the exposed $\mathrm{Al}$ bond pads.

\section{PROPERTIES OF P-TYPE POLY-SIGE}

The p-type poly-SiGe structural film was deposited in a Tystar horizontal LPCVD furnace at $450^{\circ} \mathrm{C}$ and $600 \mathrm{mT}$, using $85 \mathrm{sccm} \mathrm{SiH}_{4}, 90 \mathrm{sccm} \mathrm{GeH}_{4}$, and $50 \mathrm{sccm}$ of $10 \% \mathrm{~B}_{2} \mathrm{H}_{6} / 90 \%$ $\mathrm{SiH}_{4}$. Rutherford back scattering (RBS) indicated that the films were $\mathrm{Si}_{0.36} \mathrm{Ge}_{0,64}$. This composition is advantageous because of its combination of relatively low deposition temperature, high deposition rate of $168 \AA / \mathrm{min}$, and as-deposited polycrystalline structure. Moreover, its Ge content is less than the threshold of $70 \%$, above which significant attack by the sacrificial $\mathrm{H}_{2} \mathrm{O}_{2}$ will occur [7]. An as-deposited $3 \mu \mathrm{m}$-thick film had a sheet resistance of $6 \Omega /$ square, or a resistivity of $1.8 \mathrm{~m} \Omega-\mathrm{cm}$. Annealing did not lower the resistivity significantly, indicating that the boron was fully activated. This result is expected for Ge-rich p-type poly-SiGe films [5].

The residual stress of the p-type poly- $\mathrm{Si}_{0.36} \mathrm{Ge}_{0.64}$ was measured with the wafer curvature technique using a Flexus laser interferometer. The stress was found to be $-10 \mathrm{MPa}$ (compressive), which is quite low for an as-deposited film.

The stress gradient was determined by analyzing released cantilever beams (Fig. 1). The substrate is tilted 60 degrees, so the upper array of cantilevers appear to bend away from the substrate more than does the lower array. The deflection of 1 $\mathrm{mm}$ long beams is $70 \mu \mathrm{m}$, which corresponds to a strain gradient of $1.4 \times 10^{-4}(\mu \mathrm{m})^{-1}$. The deposition conditions have not been optimized to reduce strain gradient. 


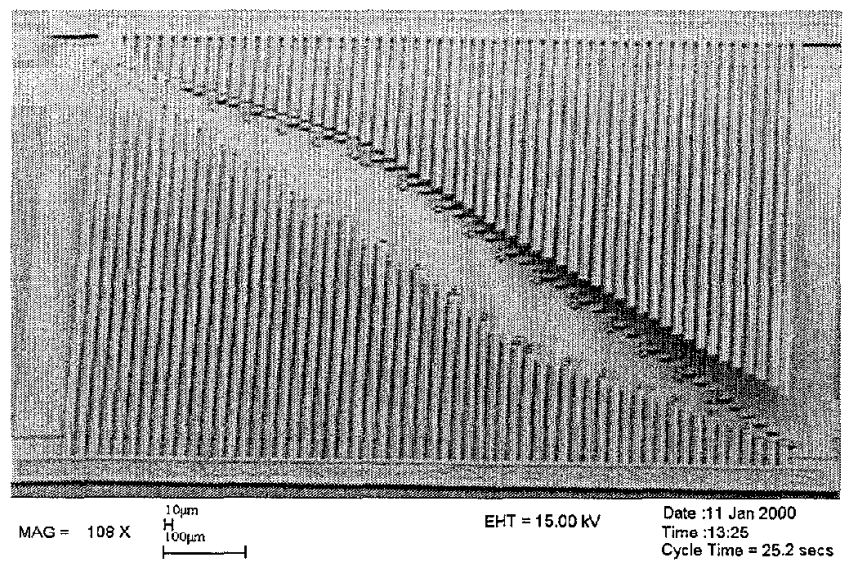

Figure 1. Array of as-deposited poly-Si $i_{0.36} G e_{0.64}$ cantilever beams. The substrate is tilted by 60 degrees, which makes the strain gradient more noticeable in the upper array.

The fracture strain of poly- $\mathrm{Si}_{0.35} \mathrm{Ge}_{0,64}$ was characterized by measuring the strain state in cantilever beams as they fractured due to in-plane bending [8]. The test structure used for these measurements is shown in Fig. 2. The fracture strain of $50 \mu \mathrm{m}$ long poly- $\mathrm{Si}_{0.36} \mathrm{Ge}_{0.64}$ beams was $1.2 \pm 0.1 \%$ (28 beams tested), whereas the fracture strain of a MCNC poly-Si was $1.9 \pm 0.2 \%$ (28 beams tested). These results indicate that the strength of poly$\mathrm{Si}_{0.30} \mathrm{Ge}_{0.64}$ is comparable to poly-Si.

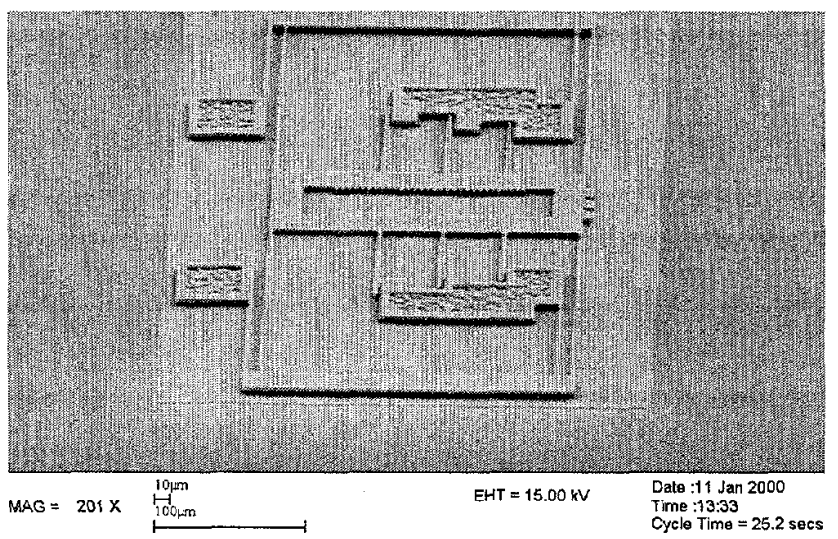

Figure 2. Poly-Si $i_{0.36} G e_{0.64}$ structure to measure fracture strain.

Poly- $\mathrm{Si}_{0.36} \mathrm{Ge}_{0.54}$ folded-flexture resonators were driven in vacuum to determine their resonant frequency and quality factor, Q. The resonators were excited with a $53 \mathrm{mVV} \mathrm{V}_{\mathrm{p} p \mathrm{p}}$ AC signal on a comb drive and $7 \mathrm{~V}$ DC on the shutle and ground plane. Measurements of $\mathrm{Q}$ were performed in a vacuum probe station at a pressure of $290 \mu$ Torr. Current from the sense electrode was fed to an off-chip transimpedance amplifier. Quality factors as high as $\sim 15,000$ were measured at a resonant frequency of $11.783 \mathrm{kHz}$ (Fig. 3). Higher quality factors may be achievable after annealing the structural film.

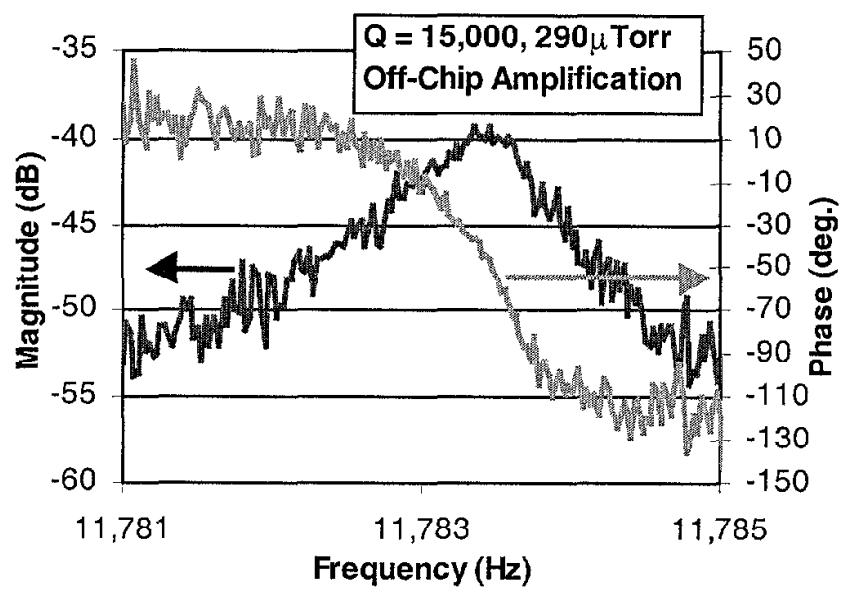

Figure 3. Frequency (amplitude and phase) characteristics of a poly-Si $i_{0.36} G e_{0.64}$ resonator.

\section{INTEGRATED POLY-SIGE MEMS PROCESS}

Transresistance amplifiers were fabricated in the UC Berkeley Microlab baseline $3 \mu \mathrm{m}$, p-well CMOS technology. The metallurgy for the CMOS was $\mathrm{Al}$ with $2 \% \mathrm{Si}$. It was demonstrated that this metallization can withstand 5 hours of annealing at $450^{\circ} \mathrm{C}$ without junction spiking problems. Electronic fabrication was completed with a $400^{\circ} \mathrm{C}$ sintering anneal. The CMOS circuitry was passivated with $1 \mu \mathrm{m}$ of low temperature oxide (LTO), which was deposited at $400^{\circ} \mathrm{C}$.

Folded-flexure resonators were fabricated using poly$\mathrm{Si}_{0.36} \mathrm{Ge}_{0.64}$ as the structural material, poly-Ge as the sacrificial material and using only conventional microfabrication equipment. Contacts were made through the LTO to connect a p-type poly-Si line to the MEMS p-type ground plane poly-Si $\mathrm{i}_{0.36} \mathrm{Ge}_{0.64^{\circ}}$. The p-type poly-Si jumper is needed since direct deposition of poly-SiGe onto aluminum is not permitted in our SiGe LPCVD furnace, which is also used for MOSFET gate research. The poly-Si jumper must be p-type to prevent diode formation. This poly-Si was doped by ion implantation along with the PMOS source and drain regions.

The poly-Si $\mathrm{i}_{035} \mathrm{Ge}_{0.54}$ films for the ground plane and structural layers were deposited in a conventional LPCVD system at $450^{\circ} \mathrm{C}$ and $600 \mathrm{mT}$ by pyrolysis of $85 \mathrm{sccm}$ of $\mathrm{SiH}_{4}, 90 \mathrm{sccm}$ of $\mathrm{GeH}_{4}$ and $50 \mathrm{sccm}$ of $10 \% \mathrm{~B}_{2} \mathrm{H}_{6} / 90 \% \mathrm{SiH}_{4}$ for $30 \mathrm{~min}$. Since SiGe does not readily nucleate on $\mathrm{SiO}_{2}$, a thin $(<5 \mathrm{~nm}$ thick) seed layer of $\mathrm{Si}$ was deposited in-situ prior to the poly-SiGe. The $0.5 \mu \mathrm{m}$-thick poly$\mathrm{Si}_{0.36} \mathrm{Ge}_{0.64}$ ground plane was patterned and etched in $25 \mathrm{~s}$ in a highdensity plasma ( $15 \mathrm{mT}$, $300 \mathrm{~W}$ top RF, $150 \mathrm{~W}$ bot. RF, $5.8 \mathrm{~cm}$ gap, 50 sccm $\mathrm{Cl}_{2}, 150$ sccm $\mathrm{HBr}$ ). The etch was continued for an additional $35 \mathrm{~s}$ to ensure removal of stringers.

A $200 \AA$-thick LTO layer was deposited on the poly$\mathrm{Si}_{0.36} \mathrm{Ge}_{0.64}$ ground plane to act as an etch stop for the Iater poly-Ge anchor etch. This layer is not essential and could be eliminated, once the poly-Ge anchor etching process is optimized. The LTO etch stop reduced the likelihood of etching significantly into the poly- $\mathrm{Si}_{0.36} \mathrm{Ge}_{0.64}$ ground plane. 
The poly Ge sacrificial layer deposition consisted of two steps. A thin seeding layer of Si was deposited with $5 \mathrm{~min}, 300$ mT, at $375^{\circ} \mathrm{C}$, and with $200 \mathrm{sccm}$ of $\mathrm{Si}_{2} \mathrm{H}_{6}$ followed by a $2 \mathrm{hr}$ and $45 \mathrm{~min}$ deposition at $375^{\circ} \mathrm{C}$, with $220 \mathrm{sccm}$ of $\mathrm{GeH}_{4}$, which resulted in a $2.8 \mu \mathrm{m}$ thick film. The anchor windows were etched in $135 \mathrm{~s}$ using the same plasma chemistry used to etch the ground plane. It should be noted that standard wafer cleaning procedures are not possible whenever poly-Ge is exposed, because poly-Ge is rapidly etched in piranha and RCA, "SC1" solutions. Solvent cleans and $\mathrm{O}_{2}$ plasma were performed instead to clean organics. Development of an alternative cleaning procedure for organic contaminants that minimizes solvent waste is desirable.
The $3 \mu \mathrm{m}$-thick structural poly- $\mathrm{Si}_{0.36} \mathrm{Ge}_{0.64}$ layer was deposited with the same conditions as the ground plane except the time was increased to 3 hours. The film was patterned with the same plasma chemistry. An endpoint signal was seen as the etching proceeded into the underlying poly-Ge after $165 \mathrm{~s}$, and etching proceeded for an additional $15 \mathrm{~s}$ to clear stringers.

Structures were released in $80^{\circ} \mathrm{C}_{2} \mathrm{O}_{2}$ for 2 hours. Dice were rinsed in water and methanol and then dried using the $\mathrm{CO}_{2}$ critical point drying technique. Figure 4 is a schematic cross-sectional view of the completed device. Figure 5 consists of SEM images of a resonator fabricated next to an amplifier and a resonator fabricated on top of the amplifier.

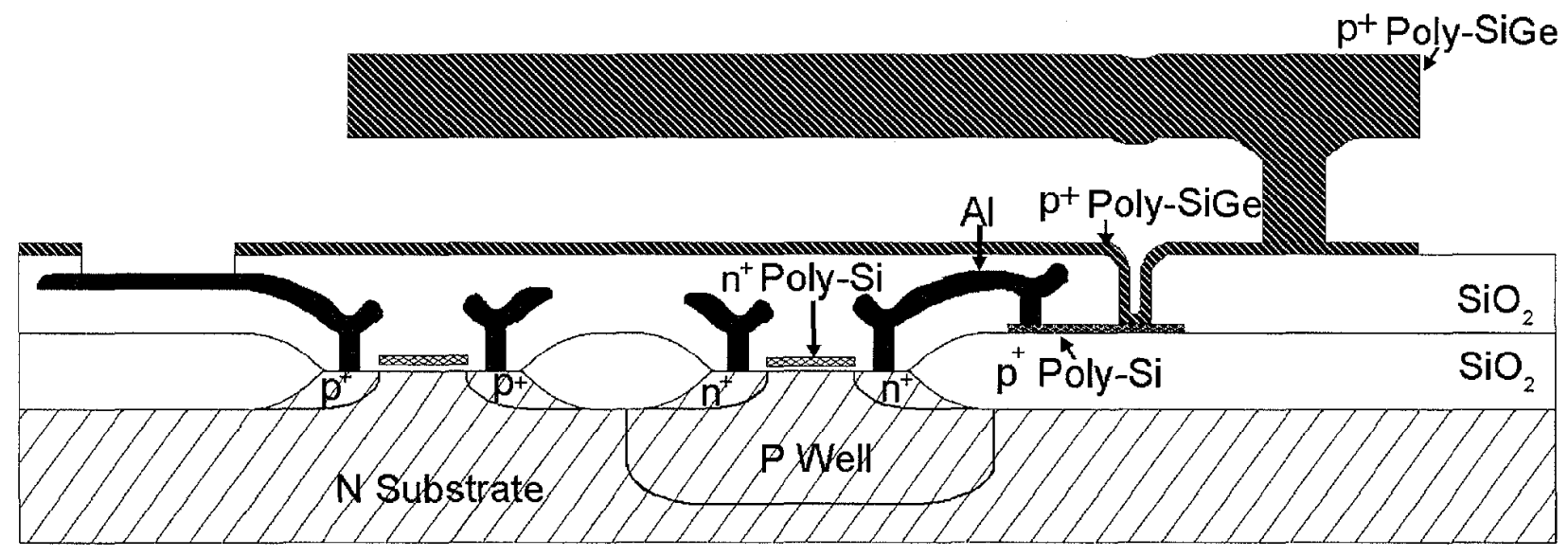

Figure 4. Schematic cross-sectional view of the fabricated CMOS and MEMS structures.
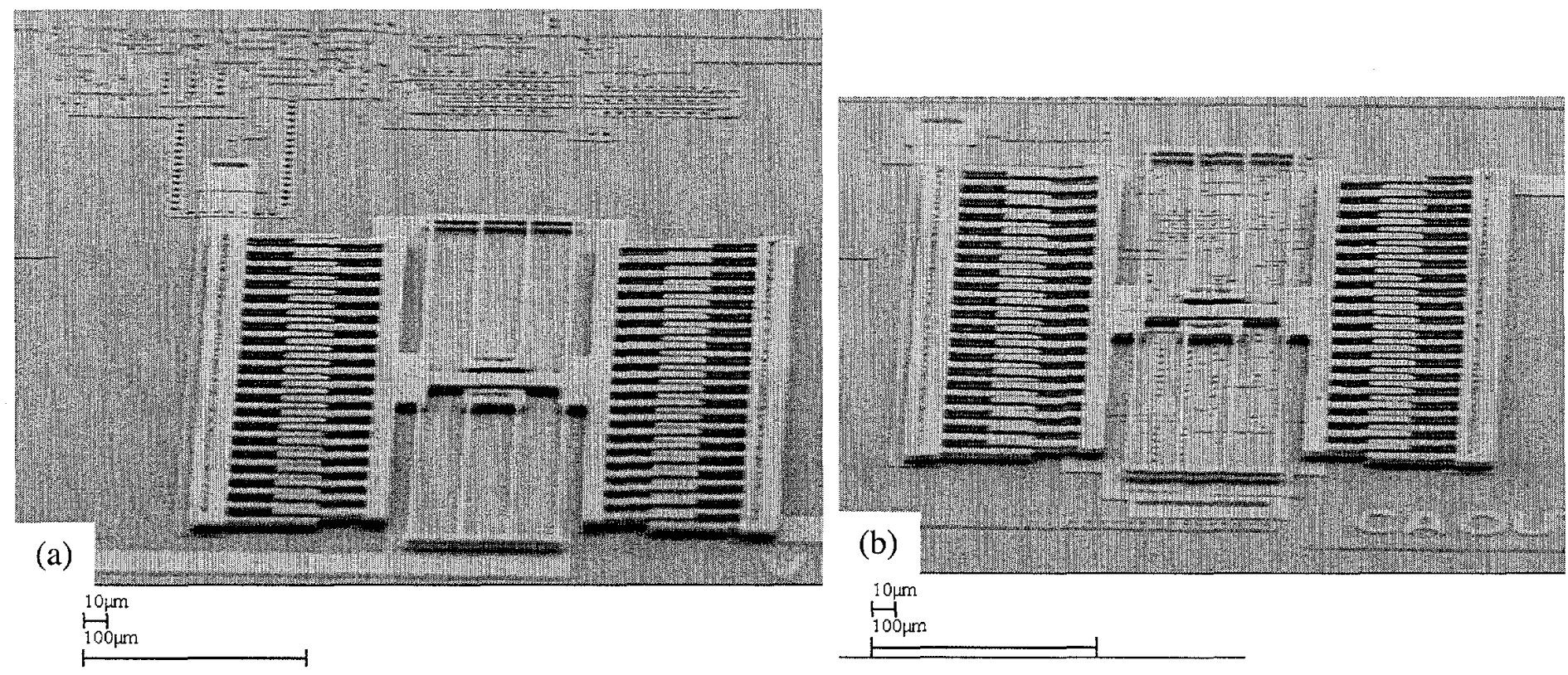

Figure 5. SEMs of fabricated poly-SiGe resonators fabricated (a) adjacent to a CMOS amplifier and (b) on top of a CMOS amplifier. Note the area reduction in fabricating $M E M S$ structures on top of electronics. 
Processing of the poly-SiGe resonators did not degrade the performance of the transistors. However, the NMOS transistors had significant leakage even hefore the processing of the MEMS structures. Secondary ion mass spectrometry (SIMS) of a monitor wafer indicated that the boron concentration in the "p-well" was below that of the n-type substrate dopant concentration. Therefore there was no p-well. New wafers are currently being processed.
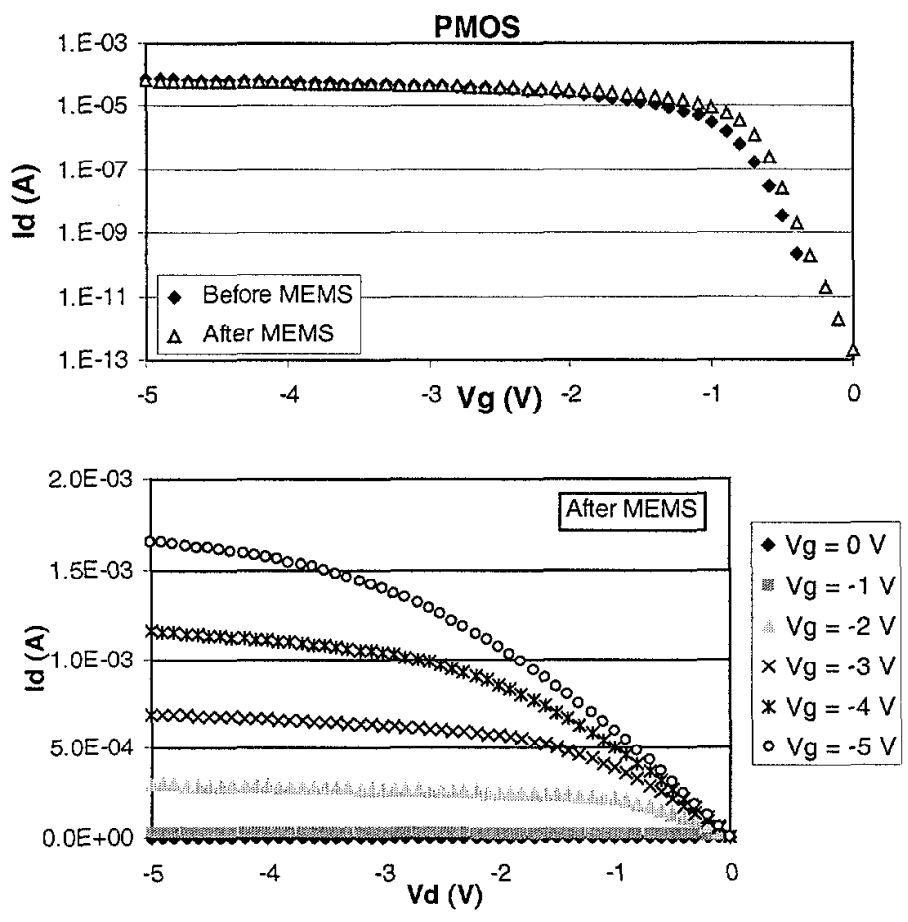

Figure 6. PMOS characteristics with $W / L=50 \mu \mathrm{m} / 3 \mu \mathrm{m}$ before and after processing of the poly-SiGe resonators.

\section{CONCLUSIONS}

A poly-SiGe structural/poly-Ge sacrificial material MEMS technology has been demonstrated which allows the integration of surface microstructures directly on top of standard electronics. No special passivation or other processing is needed to protect the CMOS layers. Stacking the MEMS on the sense amplifier drastically reduces the parasitic capacitance and resistance of the MEMS-CMOS interconnects. P-type poly-SiGe has such high dopant activation and mobility that annealing the structural film is not necessary, thus reducing the thermal budget and process complexity. No special passivation or other processing is needed to protect the CMOS layers. The etchant of the sacrificial poly-Ge, $\mathrm{H}_{2} \mathrm{O}_{2}$, does not require any special steps to protect the electronics, is safe to handle, and does not attack exposed bond pads, which further simplifies processing.

\section{REFERENCES}

1. M. Biebl, G. T. Mulhern and R. T. Howe, "Low in situ phosphorus doped polysilicon for integrated MEMS," Technical Digest, 8th International Conference on Solid-State Sensors and Actuators - Transducers 95/Eurosensors IX (Stockholm, Sweden), Vol. 1, pp. 198-201, 1995.

2. A.E. Franke, D. Bilic, D.T.Chang, P.T. Jones, T.-J. King, R.T. Ilowe, G.C. Johnson, MEMS '99, Orlando, CA, January 1999, pp. 630-7.

3. B. Li, B. Xiong, L. Jiang, Y. Zohar, and M. Wong, "Germanium as a Versatile Material for Low-Temperature Micromaching," Journal of Microelectromechanical Systems, 366, Vol. 8, No. 4, (1999).

4. T.-J. King and K. C. Saraswat, "Deposition and properties of low-pressure chemical-vapor deposited polycrystalline silicongermanium films," Journal of the Electrochemical Society, Vol. 141, No. 8, pp. 2235-2241, 1994.

5. T.-J. King, J. P. McVittic, K. C. Saraswat and J. R. Pfiester, "Electrical properties of heavily doped polycrystalline silicongermanium films," IFEE Transactions on Flectron Devices, Vol. 41, No. 2, pp. 228-232, 1994.

6. S. Sedky, P. Fiorini, M. Caymax, A. Verbist, and C. Baert, "Thermally insulated structures for IR bolometers, made of polycrystalline silicon germanium alloys," Technical Digest, 1997 International Conference on Solid-State Sensors and Actuators Transducers ' 97 (Chicago), pp. 237-240.

7. J.M. Heck, C.G. Keller, A.E. Franke, L. Muller, T.-J. King, R. T. Howe, Transducers '99, Sendai, Japan, June 1999, vol. 1, pp. 328-331

8. P.T. Jones, G.C. Johnson, and R.T. Howe, "Micromechanical structures for fracture testing of brittle thin films," (MEMS) ASME, DSC-Vol. 59, pp. 325-330, (1996). 